\title{
Correlation between number of mature eggs retrieved and live birth rate in IVF treatment
}

\author{
Lekshmy Rana*, Himanshu Bavishi, Falguni Bavishi
}

Department of Obstetrics and Gynecology, Bavishi Fertility Institute, Mumbai, Maharashtra, India

Received: 28 January 2017

Revised: 07 February 2017

Accepted: 02 March 2017

\author{
*Correspondence: \\ Dr. Lekshmy Rana, \\ E-mail: lek_4070@yahoo.com
}

Copyright: (C) the author(s), publisher and licensee Medip Academy. This is an open-access article distributed under the terms of the Creative Commons Attribution Non-Commercial License, which permits unrestricted non-commercial use, distribution, and reproduction in any medium, provided the original work is properly cited.

\begin{abstract}
Background: There is a strong association between the number of eggs and clinical pregnancy rates in IVF. But a few studies have shown conflicting results. Aim was to determine the relation between number of mature eggs retrieved and live birthrate in one complete IVF cycle (fresh and all frozen transfers included) and hence determine the optimum number of oocytes. Setting private IVF centre doing around 2000 cycles per year.

Methods: Retrospective analysis of 1140 infertile women between 20 and 45 years who underwent self-stimulation IVF in our centre, primary outcome studied was cumulative live birth rate in one complete IVF cycle. Secondary outcome was the number of cases of moderate and severe OHSS.

Results: Maximum LBR in patients where 10-15 egg were retrieved in fresh embryo transfer and cumulative LBR was maximum when more than 15 eggs were retrieved. No case of severe OHSS and one case of moderate OHSS in the group where more than 15 eggs were retrieved.

Conclusions: The percentage of live birth increases with increasing number of mature eggs in IVF treatment. The incidence of OHSS was negligible.
\end{abstract}

Keywords: IVF, Live birth rate, Mature eggs, OHSS

\section{INTRODUCTION}

The development of assisted reproductive technologies has revolutionized the treatment of Infertility. The $1^{\text {st }}$ IVF baby Louise Brown was born in 1978 by the pioneering efforts of Prof Edwards and Steptoe for which Prof Edwards was honoured with the Nobel Prize in medicine in 2010. The first IVF was natural cycle IVF in which one oocyte during natural cycle was retrieved. In natural cycle of a female one mature oocyte is released so that the rate of cancellation of cycle was high and success was less. ${ }^{1}$

In order to overcome that controlled ovarian hyper stimulation was introduced to facilitate multifollicular development and hence multiple oocyte and availability of more than one embryo for transfer. But this procedure can cause complication like OHSS, higher order multiple pregnancy and increased cost also. Many oocytes are discarded during various stages of laboratory procedures of IVF. ${ }^{2}$ The primary aim of IVF treatment is to achieve a live birth at term. So the critical question remains that how many mature oocytes per stimulation cycle is most suitable to achieve a live birth with low risk of complications.

Many studies have focused on the relation between oocyte number and clinical pregnancies and have shown conflicting results. Some studies have analyzed the relation in between number of oocytes and live birth rate in fresh transfer. ${ }^{1}$ Our study is to determine the association in between the number of oocytes retrieved and a live birth 
rate in fresh transfer and cumulative live birthrate. (Fresh and all frozen of a single stimulation included).

\section{METHODS}

Retrospective cohort study was conducted in Bavishi Fertility Institute Ahmedabad, India. Retrospective analysis of 1140 infertile women who underwent selfstimulation IVF in our institute from January 2014 December 2014 was done. Cycles involving oocytes donation and oocytesharing,and cryopreserved oocytes were excluded. Following patient details were evaluated age, duration of infertility, causes and types of infertility, stimulation protocol, number of total oocytes, number of M II oocytes, number of embryos transferred in fresh cycles and in the frozen cycle were recorded. The stage of embryo whether cleavage and blastocyst transferred were also recorded. The incidence of mild, moderate and severe OHSS were calculated

The outcome analyzed was live birth. Secondary outcome was the incidence of moderate to severe OHSS.The criteria set by were used to assess the severity of $\mathrm{OHSS}^{2}$.Live birth is defined as at least one baby born alive after 28 weeks.

In majority of patients, GnRH agonist long protocol was used. In a few patients GnRH antagonist protocol was also used. Down regulation was done with Lupride depot preparation $3.75 \mathrm{mg}$ on the luteal phase of previous cycle. The dose of depot was decided by the age and AMH. In patients with Low AMH $(<1)$ and age $>35$ years in $1 / 3^{\text {rd }}$ of 3.75 depot was given as down regulation. In all other patients $1 / 2$ of Lupride 3.75 was given. Once down regulation is confirmed ovarian stimulation was done using HMG, purified FSH, recombinant FSH or highly purified HMG. The initial stimulation dose was decided, based on Day 2 AFC, AMH, age and response in previous IVF cycle if any.

Initial dose of gonadotropin used varied fromin 100 to 450 units/day. Monitoring was done by transvaginal USG. Estradiol levels were done as and when required.and dose was altered accordingly. Once 2 to 3 follicles reached 16 to $18 \mathrm{~mm}$, I. HCG was given. The dose of HCG was 10,000 units to 5000unitssdepends on E2 level. OPU was done 36 hrs after the rigger.

In cycles where antagonist protocol were used, stimulation was started from day 2-3 of menstrual cycle. The flexible protocol was used. That is when one or two follicles reach $14 \mathrm{~mm}$, the antagonist injection was started in the dose of $0.25 \mathrm{mg}$ subcutaneously daily till the day of HCG.

ICSI was done in all cases which is routine protocol in our institute. Fertilization check was done 18 hours after and embryo transfer was either on day 2 or Day 3 or Day 5 depending on number and grade of of embryos and patient choice also. Gardner criteria was used for grading of day 3 embryos and blastocyst also. ${ }^{3}$ In few patients, fresh transfers was not done due to high risk of OHSS. Freezeall strategy was employed in such patients. The criteria for no fresh ET followed in our institute was as follows.

\section{Absolute criteria}

- E2 levels more than $3000 \mathrm{pg} / \mathrm{ml}$ on day of ET

- Combined ovarian volume more than 200 cubic mm on the day of ET

- Hematocrit $>45 \%$

- Free fluid more tha grade 3 or 4 on day of ET

- Severe pain, vomiting,respiratory discomfort

\section{Relative criteria}

- $\quad$ Free fluid grade 1 or 2

- Mild symptoms

- Hematocrit $41-45 \%$ or rise by $4 \%$ or more

\section{Grading of free fluid}

- $\quad$ Fluid upto cervix

- Fluid upto half of uterus

- Fluid upto fundus of uterus

- Fluid all around uterus and ovaries

If any one of the absolute or two of relative criteria were present patients were counseled for freeze all and no Fresh ET was done.

In all other patients fresh embryo transfer was done. Maximum of 3 cleavage stage embryos were transferred in patients less than 40 yrs. Maximum of 4 cleavage stage embryos were transferred in patients more than 40 yrs. Whereas maximum of 2 blastocysts were transferred in both the age groups. Luteal support was given with vaginal progesterone suppositories $600 \mathrm{mg} /$ day in divided doses. In a few patients progesterone gel was used vaginally $2 \mathrm{~g}$ twice daily. Pregnancy was confirmed by BHCG testing after 13-15 days.

\section{Statistical analysis}

The characteristics of live birth and no live birth were compared. Chi square test was used to ascertain the significance of categorical variables. The age wise distributions in all the 4 egg groups were comparable. 370 patients with live birth were categorized into 4 groups based on the number of M2 oocytes. By applying chisquare test there was a statistically significant difference between the live birth rate in each group.

\section{RESULTS}

1140 patients who underwent self-stimulated cycle were included in the study. They were divided in to 4 groups based on number of M II (mature) oocytes retrieved.

- Group A: 1 to 5 Eggs

- Group B: 6 to 10 Eggs 
- Group C: 11 to 15 Eggs

- Group D: >15 Eggs

The characteristics of the cohort are given in the Table 1, and 2 .

Table 1: Distribution of age.

\begin{tabular}{|lll|}
\hline Age (years) & Number & Percentage \\
\hline 20 to 30 & 294 & 25.8 \\
\hline 30 to 35 & 550 & 48 \\
\hline 35 to 40 & 183 & 16 \\
\hline$>40$ & 39 & 3.4 \\
\hline
\end{tabular}

Table 2: Distribution of number of eggs.

\begin{tabular}{|lllc|}
\hline 1 to 5 & 6 to 10 & 11 to 15 Eggs & $>15$ Eggs \\
Eggs & Eggs & 231 & 82 \\
\hline 329 & 497 & 231 \\
\hline
\end{tabular}

Majority were younger population. Only $19 \%$ were more than 35 and $3.4 \%$ more than 40 years. The major cause of infertility was tubal factor $(38 \%)$ followed by ovulatory dysfunction (31\%). Majority of women (82\%) produced less than 10 eggs in spite of optimal stimulation (Table 2).

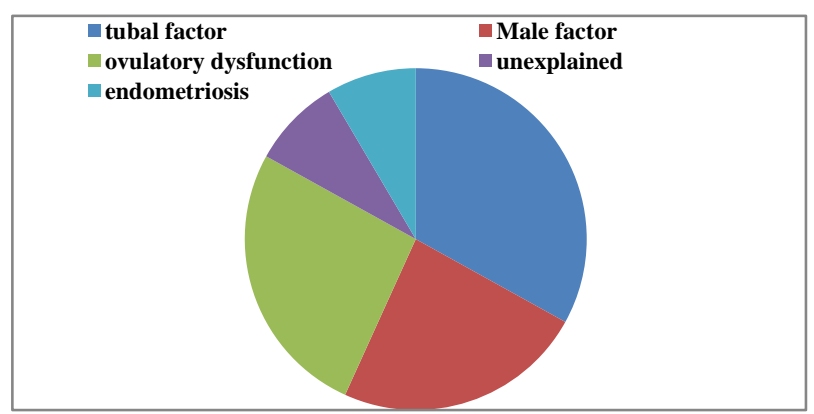

Figure 2: Causes of infertility.

As egg number increased the percentage of blastocyst transfer also increased due to increased availability of embryos. Fresh Embryo transfer was cancelled in almost $50 \%$ of patients due to high risk of OHSS, when more than 15 eggs were retrieved (Table 3 ).

Table 3: Number of fresh embryo transfers in each group.

\begin{tabular}{|llll|}
\hline 1 to 5 eggs & $\begin{array}{l}\text { Total } \\
\text { number }\end{array}$ & $\begin{array}{l}\text { Fresh } \\
\text { ET }\end{array}$ & $\begin{array}{l}\text { No fresh } \\
\text { ET }\end{array}$ \\
\hline 6 to 10 eggs & 329 & 328 & 1 \\
\hline 11 to 15 eggs & 231 & 475 & 22 \\
\hline$>15$ eggs & 82 & 187 & 44 \\
\hline
\end{tabular}

The overall live birth rate was $28 \%$. The live birth rate in fresh embryo transfer was maximum when 10 to 15 eggs were retrieved.
Table 4: Distribution of cleavage stage vs blastocyst in fresh transfer.

\begin{tabular}{|lll|}
\hline Group & Day 2/3 transfer & Blastocyst \\
\hline$<5$ eggs & $321(98 \%)$ & 7 \\
\hline $6-10$ eggs & $365(77 \%)$ & 110 \\
\hline $11-15$ & $110(59 \%)$ & 77 \\
\hline$>15$ eggs & $229(50 \%)$ & 220 \\
\hline
\end{tabular}

Table 5: Live birth rate in fresh ET.

\begin{tabular}{|lllll|}
\hline $\begin{array}{l}\text { Total no of } \\
\text { eggs }\end{array}$ & 1 to 5 & 6 to 10 & 11 to 15 & $>15$ \\
\hline $\begin{array}{l}\text { No of fresh } \\
\text { ET }\end{array}$ & 328 & 475 & 187 & 44 \\
\hline $\begin{array}{l}\text { Total live } \\
\text { birth }\end{array}$ & 61 & 145 & 78 & 14 \\
\hline Live birth rate & $18 \%$ & $30 \%$ & $41 \%$ & $31 \%$ \\
\hline
\end{tabular}

Table 6: Cumulative live birth rate (fresh +all frozen).

\begin{tabular}{|lllll|}
\hline No of eggs & $0-5$ & $6-10$ & $11-15$ & $>15$ \\
\hline $\begin{array}{l}\text { No of patients } \\
\text { completed in } \\
\text { Frozen }\end{array}$ & 329 & 487 & 211 & 68 \\
\hline $\begin{array}{l}\text { No of live birth } \\
\text { in fresh +frozen }\end{array}$ & 62 & 170 & 104 & 34 \\
\hline Cumulative LBR & $19 \%$ & $34 \%$ & $49 \%$ & $50 \%$ \\
\hline
\end{tabular}

Table 7: Incidence of OHSS.

\begin{tabular}{|llll|}
\hline $\begin{array}{l}\text { Age } \\
\text { group }\end{array}$ & $\begin{array}{l}\text { Mild } \\
\text { OHSS }\end{array}$ & $\begin{array}{l}\text { Moderate } \\
\text { OHSS }\end{array}$ & $\begin{array}{l}\text { Severe } \\
\text { OHSS }\end{array}$ \\
\hline$<5$ & 0 & 0 & 0 \\
\hline 6 to 10 & 0 & 0 & 0 \\
\hline 11 to 15 & 2 & 1 & 0 \\
\hline$>15$ & 3 & 1 & 0 \\
\hline
\end{tabular}

Table 8: LBR Age wise distribution in all groups (in fresh ET <5 M2 eggs were obtained).

\begin{tabular}{|llll|}
\hline A ge group & No of Et & Live Birth & LBR $(\%)$ \\
\hline$<30$ years & 90 & 19 & 21 \\
\hline $30-35$ years & 112 & 23 & 20 \\
\hline $35-40$ years & 63 & 4 & 6 \\
\hline$>40$ years & 23 & 1 & 4 \\
\hline
\end{tabular}

Table 9: 6 to 10 MII eggs

\begin{tabular}{|llll|}
\hline $\begin{array}{l}\text { Age group } \\
\text { years }\end{array}$ & No of ET & $\begin{array}{l}\text { Live birth } \\
\text { number }\end{array}$ & LBR $(\%)$ \\
\hline$S<30$ & 196 & 62 & 31 \\
\hline $30-35$ & 209 & 30 & 23 \\
\hline $35-40$ & 81 & 16 & 19 \\
\hline$>40$ & 11 & 0 & 0 \\
\hline
\end{tabular}


Table 10: 11 to 15 eggs.

\begin{tabular}{|llll|}
\hline Age group & No of ET & $\begin{array}{l}\text { Live birth } \\
\text { (number) }\end{array}$ & LBR (\%) \\
\hline$<30$ & 47 & 21 & 44 \\
\hline $30-35$ & 63 & 32 & 50 \\
\hline $35-40$ & 19 & 10 & 52 \\
\hline$>40$ & 5 & 1 & 25 \\
\hline
\end{tabular}

Table 11: >15 MII eggs.

\begin{tabular}{|lll|l|}
\hline $\begin{array}{l}\text { Age group } \\
\text { (years) }\end{array}$ & $\begin{array}{l}\text { Total no. } \\
\text { of ET }\end{array}$ & LBR number & $\begin{array}{l}\text { LBR } \\
(\%)\end{array}$ \\
\hline$<30$ & 12 & 5 & 41 \\
\hline $30-35$ & 10 & 6 & 60 \\
\hline $35-40$ & 6 & 3 & 50 \\
\hline
\end{tabular}

There was a strong positive association between egg number and cumulative live birth rate. In our study, also age was an independent predictor of live birth. But when the LBR in different age groups were compared, in all age groups there was a strong correlation between increasing egg number and LBR (Table 8-11).

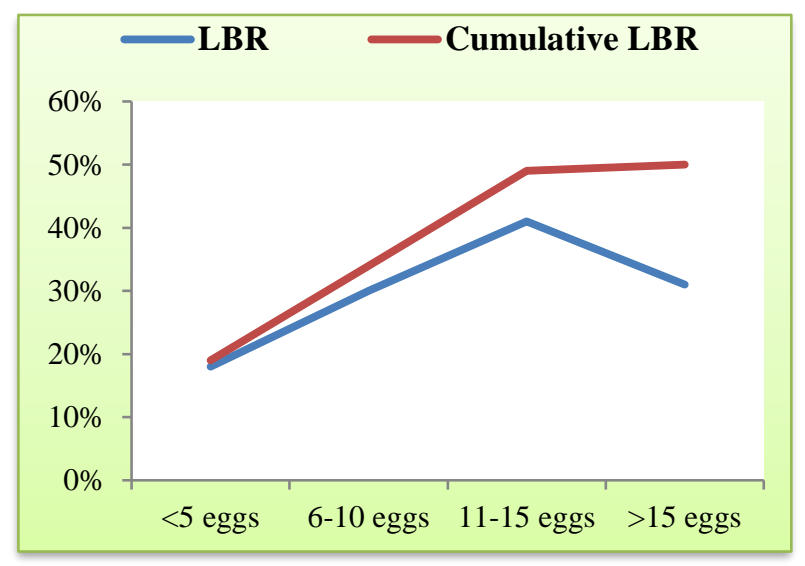

Figure 2: $L B R$ and cumulative $L B R$ in various egg groups.

\section{DISCUSSION}

IVF is an important aspect of of infertility $\mathrm{F}$ treatment. Having good number of good quality embryos can increase the success of IVF treatment. For that there is the need of good number of M2 oocytes.

The first major study showing relationship between number of eggs and live birthrate was published. ${ }^{4}$ That study has shown that 15 was the optimum egg number above and below which live birth and clinical pregnancy rate declined. But in this study the live birth rate in fresh embryo transfer cycle was calculated. They did not include the frozen thawed cycle in one study have found out that the ideal number of oocyte after a conventional long protocol is $13 .^{1}$
Female age is the strong predictor of IVF success rate. In this study also the live birthrate was more in younger patients compared to the older ( $34 \%$ vs $15 \%)$. Our study suggests that the live birth rate was maximum in the 10-15 egg group in fresh transfer. The cumulative live birthrate increased proportionately with increasing egg number. High ovarian response did not compromise live birth rate when fresh and frozen thawed transfers were included. When the oocyte number was less than 5 there was a drastic reduction in live birth rate. The results of our study matched with some studies (vandergastetal, Sunkaraetal) in a way that above and below certain number of oocytes, there was a decrease in the outcome. Our study also did not show an increased incidence of chromosomal anomalies with moderate ovarian stimulation. ${ }^{5}$

The live birth rate in same age group was compared in the different egg numbers, we observed that the live birth rate in same age group increased proportionately with increasing egg numbers. So we can say that the number of mature eggs retrieved is one of the independent predicting factors of IVF success.

The major problem when we intend to produce more number of eggs in an IVF cycle is the risk of OHSS especially in high risk patients. Another drawback which was pointed out in certain studies was the detrimental effect of supra physiological hormone levels mainly estrogen and progesterone levels on the implantation and egg quality and thereby embryo quality, which has led to the popularity of minimal stimulation protocols.

Some studies have shown a deleterious effect of supra physiological levels of estradiol on embryo quality and endometrial receptivity and it may hamper oocyte quality. ${ }^{6-8}$

Study in 2006 showed that in high responders even though the proportion of immature oocytes were more, pregnancy outcome is not impaired. ${ }^{9}$ This is supported by our study. In a recent study showed that high ovarian response $(>18$ oocytes) did not compromise the chances of pregnancy even in fresh cycle. ${ }^{10}$ One study showed that even in case of OHSS implantation rate is not compromised. ${ }^{11}$

It is well established that the incidence of OHSS increases proportionately with increased ovarian response. ${ }^{12,13}$ OHSS can be prevented by giving agonist trigger in antagonist cycle. But in our study, agonist protocol was used in majority of patients, hence this could not be applied. So freezing of all embryos in high risk patients was used. ${ }^{14}$ The criteria used in our institute was as already mentioned above. That was termed as Bavishi criteria, which took into account factors like estradiol level, combined volume of both ovaries on the day of ET, hematocrit on day of ET and symptoms of patient and free fluid in pelvis. The Grading of free fluid was already mentioned. There was not a single case of Severe OHSS reported in our study. 
The limitations of this study is that this was a retrospective study. We could not match the variables like cause of infertility, in each groups. Some variables likerelation between egg number and marker so ovarian reserve $(\mathrm{AMH})$ was not analysed in this study.

\section{CONCLUSION}

Majority of Indian women in this study had produced $<10$ eggs in spite of optimal stimulation protocol. The percentage of blastocyst transfer increase with increasing egg number. The patients with more than 10 eggs were encouraged to go for blastocyst culture due to availability of more embryos. In fresh embryo transfer the LBR increased with increasing number of oocytes upto 15. After 15 the LBR in fresh ET decreased but not drastically .The overall LBR in Fresh ET was 28. In majority of patients in more than 15 egg group no ET was done in fresh cycle due to high risk of OHSS. So moderate stimulation of ovaries can be done in IVF cycle for an effective outcome with minimal complications.

\section{Funding: No funding sources}

Conflict of interest: None declared

Ethical approval: The study was approved by the Institutional Ethics Committee

\section{REFERENCES}

1. Gaast MH, Eijkemans MJ, Net JB, Boer EJ, Burger CW. Optimum number of oocytes for a successful first IVF treatment cycle. Reprod Biomed Online. 2006;13:476-80.

2. Golan A, Ronel R, Herman A, Soffer Y, Weinraub Z, EInge GB, et al. Oocyte number per live birth in IVF: were Steptoe and Edwards less wasteful? Hum Reprod. 2005;20:588-92.

3. Gardner DK, Lane M, Stevens J, Schlenker T, Schoolcraft WB. Blastocyst score affects implantation and pregnancy outcome: towards a single blastocyst transfer. Fertil Steril. 2000;73:1155-8.

4. Sunkara SK, Rittenberg V, Fenning N, Bhattacharya S, Zamora J, Coomarasamy A. Association between the number of eggs and live birth in IVF treatment: an analysis of 400135 treatment cycles. Hum Reprod. 2011;26(7):1768-74.

5. Labarta E, Bosch E, Alamá P, Rubio C, Rodrigo L, Pellicer. A moderate ovarian stimulation does not increase the incidence of human embryo chromosomal abnormalities in in-vitro fertilization cycles. J Clin Endocrinol Metab. 2012;97:1987-94.
6. Mitwally MF, Bhakoo HS, Crickard K, Sullivan M, Batt RE, Yeh J. Estradiol production during controlled ovarian hyper stimulation correlates with treatment outcome in women undergoing in vitro fertilizationembryo transfer. Fertil Steril. 2006;86:588-96.

7. Blondin P, Coenen K, Guilbault LA, Sirard M. Super ovulation can reduce the developmental competence of bovine embryos. Theriogenology. 1996;46:1191203.

8. Baart EB, Martini E, Eijkemans MJ, Opstal D, Beckers NG, Verhoeff A et al. Milder ovarian stimulation for in-vitro fertilization reduces aneuploidy in the human preimplantation embryo: a randomized controlled trial. Hum Reprod. 2000;22:65-9.

9. Kok JD, Looman CW, Weima SM, Tevelde E. A high number of oocytes obtained after ovarian hyperstimulation for in vitro fertilization or intracytoplasmic sperm injection is not associated with decreased pregnancy outcome. Fertil Steril. 2006;85:918-24.

10. Fatemi HM, Doody K, Griesinger G, Witjes H, Mannaerts B. High ovarian response does not jeopardize ongoing pregnancy rates and increases cumulative pregnancy rates in a GnRH-antagonist protocol. Hum Reprod. 2013;28:442-52.

11. Fa'bregues F, Pen arrubia J, Vidal E, Casals G, Vanrell JA, Balasch J. Oocyte quality in patients with severe ovarian hyperstimulation syndrome: a selfcontrolled clinical study. Fertil Steril. 2004;82:82733.

12. Nastri CO, Ferriani RA, Rocha IA, Martins WP. Ovarian hyperstimulation syndrome: pathophysiology and prevention. J Assist Reprod Genet. 2010;27:121-8.

13. Grossman LC, Michalakis KG, Browne H, Payson MD, Segars JH. The pathophysiology of ovarian hyperstimulation syndrome: an unrecognized compartment syndrome. Fertil Steril. 2010;94:13928.

14. Verwoerd GR, Mathews T, Brinsden PR. Optimal follicle and oocyte numbers for cryopreservation of all embryos in IVF at risk of OHSS. Reprod Biomed Online. 2008;17:312-7.

Cite this article as: Rana L, Bavishi $\mathrm{H}$, Bavishi $\mathrm{F}$. Correlation between number of mature eggs retrieved and live birth rate in IVF treatment. Int J Reprod Contracept Obstet Gynecol 2017;6:1625-9. 